\title{
The Nicotinic Acetylcholine Receptor as a Target for Antidepressant Drug Development
}

\author{
Noah S. Philip, Linda L. Carpenter, Audrey R. Tyrka, and Lawrence H. Price \\ Mood Disorders Research Program, Butler Hospital and Department of Psychiatry and Human Behavior, \\ Alpert Medical School of Brown University, Providence, RI 02906, USA \\ Correspondence should be addressed to Noah S. Philip, noah_philip@brown.edu
}

Received 26 January 2012; Accepted 28 February 2012

Academic Editors: A. Czurko, S. M. Dursun, H. Luddens, and P. Stratta

Copyright ( $\odot 2012$ Noah S. Philip et al. This is an open access article distributed under the Creative Commons Attribution License, which permits unrestricted use, distribution, and reproduction in any medium, provided the original work is properly cited.

An important new area of antidepressant drug development involves targeting the nicotinic acetylcholine receptor (nAChR). This receptor, which is distributed widely in regions of the brain associated with depression, is also implicated in other important processes that are relevant to depression, such as stress and inflammation. The two classes of drugs that target nAChRs can be broadly divided into mecamylamine- and cytisine-based compounds. These drugs probably exert their effects via antagonism at $\alpha 4 \beta 2 \mathrm{nAChRs}$, and strong preclinical data support the antidepressant efficacy of both classes when used in conjunction with other primary antidepressants (e.g., monoamine reuptake inhibitors). Although clinical data remain limited, preliminary results in this area constitute a compelling argument for further evaluation of the nAChR as a target for future antidepressant drug development.

\section{Introduction}

Depression is one of the most common psychiatric illnesses in the world and has a significant public health impact. Despite the abundance of medications available, many affected patients do not achieve relief. In the largest comparative efficacy study of antidepressant treatment, the Sequenced Treatment of Alternatives to Relieve Depression $\left(\mathrm{STAR}^{*} \mathrm{D}\right)$ [1], about half of patients receiving initial treatment with antidepressants responded, but only a third reached remission, and up to a third never reached remission despite multiple trials of various medications and combinations. Most of the antidepressant drugs used in STAR*D directly increase synaptic availability of monoamines, often via reuptake inhibition. Clearly, new and better interventions that utilize novel mechanisms of action are needed.

Nicotinic acetylcholine receptor (nAChR) modulation is an area with significant promise for future antidepressant drug development. The nAChR literature builds upon studies from the 1970s that advanced a cholinergic theory of depression, in which excessive cholinergic signaling could lead to depressive symptoms. This area of research was largely abandoned due to issues regarding safety and tolerability of the compounds available at that time. More recently, with the development of new molecules targeting this system, significant interest in the antidepressant properties of $\mathrm{nAChR}$ modulation has reemerged. This paper reviews the available literature on the use of nAChR modulators for treating depression, building on previous reports [2]. Their use for other indications, such as smoking cessation and cognitive enhancement, has been addressed elsewhere [3-6].

\section{The Nicotinic Acetylcholine Receptor}

In their common ability to respond to acetylcholine binding, $\mathrm{nAChRs}$ are functionally related to muscarinic acetylcholine receptors (mAChRs). However, whereas $\mathrm{mAChRs}$ activate ion channels via G-protein coupling, nAChRs are ligandgated ion channels and exhibit affinity for nicotine as well as acetylcholine. Activated nAChRs cause an influx of cations, which affect membrane polarity and intracellular messenger cascades [7]. nAChRs are distributed throughout both the peripheral and central nervous systems, although the focus here is on central nervous system (CNS) nAChRs. Formed of five pentameric units, nAChRs can be categorized as either high or low affinity. High-affinity nAChRs are heteromers of $\alpha$ - and $\beta$-subunits, are antagonized by compounds 
such as dihydro- $\beta$-erythroidine and mecamylamine and are stimulated by low doses of the $\alpha 4 \beta 2$ partial agonist varenicline. Low-affinity nAChRs, on the other hand, are $\alpha$ homopentamers and are antagonized by $\alpha$-bungarotoxin and methyllycaconitine [7].

CNS nAChRs are widely distributed throughout brain regions associated with depression, such as the ventral tegmental area, locus coeruleus, and dorsal raphe nucleus. Their primary action is thought to be in the regulation of other neurotransmitter systems [8], particularly dopamine, via direct [9] and indirect effects [7, 10-13], and the n-methyl-D-aspartate (NMDA) glutamatergic system [14]. nAChRs are also involved in other neurobiological systems that are dysregulated in depression, such as the hypothalamic-pituitary-adrenal axis. nAChRs are found on presynaptic terminals of corticotropin-releasing factor (CRF) neurons [15], and nAChR antagonists can block CRF release [16]. Similarly, nAChRs appear to play a role in inflammation, which is the subject of increasing interest with regard to depression [17]. nAChRs regulate the socalled cholinergic ascending anti-inflammatory pathway, in which activation of the vagus nerve diminishes inflammation through decreased peripheral macrophage activity mediated via $\alpha 7 \mathrm{nAChRs}[18,19]$.

\section{3. nAChRs and Depression: Antidepressant Effects of Nicotine}

Nicotine, the classic nAChR ligand, has been demonstrated to have antidepressant properties in both preclinical and clinical studies. In rodents, several studies of nicotine administration have identified antidepressant-like effects during the forced swim test (FST) and tail suspension test (TST) [20-23], two preclinical models used to investigate potential antidepressant effects of candidate compounds [24, 25]. Complementing these experiments, clinical studies have shown that transdermal nicotine can improve mood in both depressed smokers [26] and nonsmokers [27]. Antidepressant effects of nicotine are thought to be due to initial activation of the $\mathrm{nAChR}$, followed by rapid desensitization that leads to long-term antagonism [28-32].

\section{Targeting nAChRs for Depression}

Most research targeting $\mathrm{nAChRs}$ for depression has focused on several parent compounds and their derivatives. The two principal compounds evaluated to date are mecamylamine, a nonspecific nAChR antagonist, and the plant alkaloid cytisine, which has been investigated for its effects on $\alpha 4 \beta 2$ nAChRs. The following sections are organized by parent compound, starting with a discussion of the preclinical literature supporting use for depression, then followed by clinical evidence, if available.

\section{Mecamylamine}

Mecamylamine is a nonselective and noncompetitive antagonist at nAChRs. Derived from camphene, mecamylamine was first developed in the 1950s and utilized clinically as an antihypertensive agent [33], although its use was limited by anticholinergic side effects at therapeutic doses. After preliminary clinical studies that showed efficacy for mecamylamine in augmenting the efficacy of primary antidepressants [34], a number of preclinical studies evaluated its use in animal models of depression. Popik et al. [35] first demonstrated that mecamylamine, combined with the tricyclic antidepressant (TCA) imipramine or the selective serotonin reuptake inhibitor (SSRI) citalopram, improved immobility time during the FST. This study also investigated dihydrobetaerythiodine, a selective $\alpha 4 \beta 2$ nAChR antagonist, which increased the antidepressant-like effects of imipramine. Other studies consistently showed that racemic mecamylamine could improve performance on the FST or TST, either alone [36-39] or in combination with primary antidepressants [20,37]. Administration of the s-enantiomer of mecamylamine, s-mecamylamine, also resulted in improvement in FST and behavioral despair tests [40]. These effects are driven by antagonism at the $\alpha 4 \beta 2 \mathrm{nAChR}$, as knockout mice for this specific subtype of nAChR showed no effect of mecamylamine administration [37]. While most of these studies were positive, negative findings were reported by Andreasen and Redrobe [20]. They found no effect of mecamylamine when used alone or in combination with citalopram; only citalopram had significant effects on FST performance (Table 1).

These preclinical studies laid the foundation for further clinical trials of mecamylamine as an augmenting agent for the treatment of depression. Shytle et al. [34] first showed that mecamylamine improved depressive symptoms and irritability in children and adolescents with Tourette's disorder, a neuropsychiatric condition characterized by multiple physical and vocal tics (i.e., stereotyped motor movements or vocalizations) [41]. George et al. [42] subsequently conducted an 8-week, double-blind, placebo-controlled trial of mecamylamine augmentation, administering mecamylamine $10 \mathrm{mg} /$ day augmentation to patients with at least moderate depressive symptoms who had been on an SSRI for at least 3 months with little or no response. The investigators additionally hypothesized that smokers would have a more robust response to mecamylamine, as nAChRs are thought to be upregulated in smokers due to chronic nicotine selfadministration [43]. Overall, mecamylamine augmentation resulted in significant improvement in depressive symptoms compared to placebo. In contrast to the investigators' hypothesis, there was a trend $(P=0.06)$ for nonsmoking patients to have a greater response than smokers, suggesting that mecamylamine might be more efficacious in the former group.

Larger commercial trials of racemic mecamylamine and s-mecamylamine as augmentation agents for depression were subsequently conducted. While the results are not in the public domain, outcomes from the racemic mecamylamine trial were reportedly positive, and phase II results for smecamylamine were also reportedly positive, with a large effect size [6]. However, preliminary reports from a large, multicenter, double-blind phase III trial failed to meet the primary endpoint of significant improvement in depressive 
TABLE 1: Evidence for MEC/S-MEC in mouse models of depression.

\begin{tabular}{lccc}
\hline Study & Compound(s) & MEC/s-MEC dose & Results \\
\hline Popik et al. [35] & MEC + CTP & $0.025 \mathrm{mg} / \mathrm{kg}$ & Improved FST \\
\hline Rabenstein et al. [36] & MEC + IMI & $1 \mathrm{mg} / \mathrm{kg}$ & Improved FST and TST \\
\hline Caldarone et al. [37] & MEC & $0.50,0.75$, or $1.0 \mathrm{mg} / \mathrm{kg}$ & Improved FST/TST \\
& MEC + AMI & & Further improved FST/TST \\
\hline Andreasen et al. [38] & MEC & 3 or $10 \mathrm{mg} / \mathrm{kg}$ & Improved FST/TST \\
\hline Andreasen and Redrobe [20] & MEC + CTP & $1,3 \mathrm{mg} / \mathrm{kg}$ & No effect on FST/TST \\
\hline Mineur et al. [39] & MEC + REB & $1 \mathrm{mg} / \mathrm{kg}$ & Improved FST/TST \\
\hline Lippiello et al. [40] & MEC & $3 \mathrm{mg} / \mathrm{kg}$ & Improved FST \\
\hline
\end{tabular}

Notes: ${ }^{\mathrm{a}} 1-10 \mathrm{mg} / \mathrm{kg}$ doses tested, and only doses at 3 and $10 \mathrm{mg} / \mathrm{kg}$ with improved FST/TST.

Abbreviations: MEC: mecamylamine; CTP: citalopram; IMI: imipramine; AMI: amitriptyline: REB: reboxetine; S-MEC: s-mecamylamine; FST: forced swim test; TST: tail suspension test.

symptoms [44]. There could be many reasons for this negative result, including issues differing efficacy in smokers versus nonsmokers. Cultural influences may also have impacted clinical trial outcome measures, as the phase II study was completed largely in India and, to a lesser extent, the United States, whereas the phase III study was conducted in European countries. Since this study is not in the public domain, it is difficult to evaluate possible explanations for the negative results, and it would seem premature to dismiss the potential antidepressant effects of mecamylamine without fuller access to the data.

\section{Cytisine and Cytisine-Based Compounds}

6.1. Cytisine. Cytisine, a partial agonist at the $\alpha 4 \beta 2 \mathrm{nAChR}$ [39], is extracted from the seeds of the Cytisus labornum (Golden Rain Acacia) [45]. It was first developed as an inexpensive smoking cessation agent in former Eastern Bloc countries in the 1950s and continues to be available as an over-the-counter smoking cessation agent in Russia. It constitutes the parent structure for other pyridine-like compounds, such as varenicline, dianicline, and sazetidine.

Preclinical studies consistently have demonstrated antidepressant-like effects of cytisine in acute $[39,46]$ and chronic [39] rodent models. Cytisine administration has been linked to reduced expression of c-fos, an immediate early gene transcription factor reflecting neuronal activity [47] that downregulates in the context of chronic antidepressant treatment [48]. Other cytisine-based partial $\alpha 4 \beta 2$ nAChR agonists also have antidepressant-like effects [46], which further underscores the potential of this parent compound for treating depression. To our knowledge, there are no clinical studies investigating cytisine for depression, although the one available smoking cessation study found little effect of the drug on either smoking cessation or depressive symptoms [49]. These findings could be explained by cytisine's limited ability to affect CNS $\alpha 4 \beta 2$ nAChRs [50].

6.2. Varenicline. Varenicline, a partial agonist at the highaffinity $\alpha 4 \beta 2 \mathrm{nAChR}$ and full agonist at the $\alpha 7 \mathrm{nAChR}$, was synthesized from its parent compound cytisine [51] in the pursuit of novel drugs for smoking cessation. In preclinical models, varenicline produced mild antidepressant-like effects during the FST, comparable to the SSRI sertraline but less than the TCA amitriptyline [52]. However, when administered in combination with sertraline, varenicline significantly improved FST performance. These effects were seen at lower doses of varenicline, which suggested an inverse dose-dependent effect [52]. One further study found no effect of varenicline on the FST and TST, but varenicline was administered in that study as a monotherapy, and most doses tested $(0.01-1 \mathrm{mg} / \mathrm{kg})$ were lower than those of other studies $(0.178-5.6 \mathrm{mg} / \mathrm{kg}$ ) [53] (Table 2). Large clinical trials for smoking cessation showed improvement in depressive symptoms associated with nicotine withdrawal $[54,55]$, and subsequent examinations found improved mood and cognition in subjects using varenicline for smoking cessation [56]. A small open-label study of varenicline augmentation in smokers with depression showed significant improvement in treatment-resistant patients [57].

One concern about the clinical use of varenicline has been neuropsychiatric side effects, such as increased depression or psychosis [60-62]. Although one report found that varenicline was associated with an increased rate of such events [63], other large studies have generally found no difference between varenicline and other medications for smoking cessation [64-67], findings that have been replicated in studies sponsored by the U.S. Food and Drug Administration [68]. An important consideration in evaluating this issue are the adverse effects upon mood of smoking cessation itself, which has been shown to induce major depressive episodes and suicidality in susceptible individuals [69].

6.3. Dianicline. Dianicline, also derived from cytisine, was developed to target high-affinity $\alpha 4 \beta 2$ nAChRs. The preclinical profile of dianicline is similar to that of varenicline, with its ability to affect dopamine release [70], although it has relatively weak CNS penetration [71]. To our knowledge, there are no studies evaluating the effect of this compound on preclinical models of depression. The one available clinical 
TABLE 2: Evidence for cytisine and cytisine-based compounds in mouse models of depression.

\begin{tabular}{lccc}
\hline Study & Compound(s) & CYT-compound dose & Results \\
\hline Mineur et al. [39] & CYT & $1.5 \mathrm{mg} / \mathrm{kg}$ a & Improved FST/TST \\
\hline \multirow{2}{*}{ Mineur et al. [46] } & CYT & $1,1.5 \mathrm{mg} / \mathrm{kg}$ & Improved FST/TST \\
& 3-pyr-CYT & & Improved FST/TST \\
& 5-Br-CYT & No effect on FST/TST & Improved FST \\
Rollema et al. [52] & VNCL & $0.178,0.56,1,1.78,3.2,5.6 \mathrm{mg} / \mathrm{kg}$ & Improved FST \\
\hline Kozikowski et al. [58] & VNCL + SERT & $0.56,5.6 \mathrm{mg} / \mathrm{kg}$ & Improved FST \\
\hline Turner et al. [53] & SAZ-A & $1 \mathrm{mg} / \mathrm{kg}$ & No effect on FST \\
& VNCL & $0.01,0.1,1 \mathrm{mg} / \mathrm{kg}$ & Improved FST \\
\hline Caldarone et al. [59] & SAZ-A & $1 \mathrm{mg} / \mathrm{kg}$ & Improved FST \\
& VNCL & $0.3,1$, and $3 \mathrm{mg} / \mathrm{kg}$ & Improved FST \\
\hline
\end{tabular}

Notes: ${ }^{\mathrm{a}} 0.2,0.6,1.0$, and $1.5 \mathrm{mg} / \mathrm{kg}$ CYT tested.

${ }^{\mathrm{b}}$ No CNS penetration.

${ }^{c}$ Low dose VNCL $(0.56 \mathrm{mg} / \mathrm{kg})$ combined with low dose SERT $(1.78 \mathrm{mg} / \mathrm{kg})$ produced no significant effect on FST performance.

${ }^{\mathrm{d}} \mathrm{SAZ}-\mathrm{A}$ at doses of $0.05-0.5 \mathrm{mg} / \mathrm{kg}$ had no effect on FST performance.

Abbreviations: CYT: cytisine; 3-pyr-CYT: 3-[pyridin-3'-yl]-cytisine; 5-Br-CYT: 5-bromo-cytisine; VNCL: varenicline; SERT: sertraline; SAZ-A: sazetidine-A; FST: forced swim test; TST: tail suspension test.

study of dianicline for smoking cessation was negative, with little effect on smoking outcomes or depressive symptoms [72], as might be expected for a medication with weak CNS penetration.

6.4. Sazetidine-A. Sazetidine-A is one of the newest compounds targeting the $\alpha 4 \beta 2 \mathrm{nAChR}$. Sazetidine-A is thought to act in a different manner than other cytisine analogues, in that it binds to and desensitizes $\alpha 4 \beta 2 \mathrm{nAChRs}$ without activation and acts principally on the $\beta 2$ subunit $[59,73]$. Kozikowski et al. [58] showed that acute administration of sazetidine-A improved performance during the FST, to a degree comparable to that of the TCA desipramine. Several other recent studies have also shown antidepressantlike effects during the TST and FST [53, 59] (Table 2). These promising findings have prompted investigations into sazetidine-A analogues to evaluate potential antidepressantlike activity [74-76]. To our knowledge, there are no studies investigating sazetidine-A as an antidepressant augmenting agent in preclinical models, nor are there clinical studies investigating sazetidine-A for depression. However, given the preclinical data for related compounds, we anticipate that preclinical augmentation studies and clinical studies could yield positive results.

\section{7. $\alpha 7$ nAChR Agonists}

The structurally distinct $\alpha 7 \mathrm{nAChR}$, composed of five identical $\alpha 7$ subunits, has been investigated for cognitive disorders and schizophrenia [33], but older data suggest that $\alpha 7$ agonists may have antidepressant activity. Studies from the late 1990s suggested that $\alpha 7$ receptors were required for the antidepressant effects of the SSRI fluoxetine [77], and it is possible that preclinical antidepressant-like effects of varenicline may be, in part, due to agonism at this receptor. Compounds targeting this $\mathrm{nAChR}$ have thus far generated contradictory findings. PNU-282987 has been shown to exhibit antidepressant-like effects when administered in combination with other antidepressants [78], but other studies have not replicated this [79]. While these studies may have been confounded by the specific mouse strains used [80], it is unlikely this compound will be tested in humans due to its potential for serious cardiac side effects [81]. Other $\alpha 7$ nAChR agonists that can improve FST performance, such as SSR180711, are still under investigation [79]. Although findings are still largely preliminary, they suggest that further study of the role of this receptor in depression is warranted.

\section{Conclusion}

There is clear evidence that $\mathrm{nAChRs}$ are a promising area for drug development in depression. Preclinical data document the greatest potential for compounds that target the $\alpha 4 \beta 2$ $\mathrm{nAChR}$, with the sazetidine-A findings suggesting that the $\beta 2$ component is necessary for antidepressant activity. All of these drugs appear to be most efficacious when administered in combination with other antidepressants and at low dosages. The relatively limited clinical data available to date indicate unlikely efficacy for cytisine and dianicline, possible efficacy for varenicline, and promising efficacy for mecamylamine as augmentation agents. It is unclear if these compounds will have differential efficacy in smoking or nonsmoking populations, and this should be an important consideration in future clinical trials. Taken together with the known limits of available antidepressant medications, the preclinical and clinical evidence provides a strong argument for future antidepressant drug development targeting this relatively unexplored receptor. 


\section{Conflict of Interests}

The authors attest, to the best of their knowledge, that they have no conflicts of interests in relation to this paper to disclose.

\section{References}

[1] M. H. Trivedi, A. J. Rush, S. R. Wisniewski et al., "Evaluation of outcomes with citalopram for depression using measurementbased care in $\mathrm{STAR} * \mathrm{D}$ : implications for clinical practice," American Journal of Psychiatry, vol. 163, no. 1, pp. 28-40, 2006.

[2] N. S. Philip, L. L. Carpenter, A. R. Tyrka, and L. H. Price, "Nicotinic acetylcholine receptors and depression: a review of the preclinical and clinical literature," Psychopharmacology, vol. 212, no. 1, pp. 1-12, 2010.

[3] O. Sabri, K. Kendziorra, H. Wolf, H. J. Gertz, and P. Brust, "Acetylcholine receptors in dementia and mild cognitive impairment," European Journal of Nuclear Medicine and Molecular Imaging, vol. 35, no. 1, pp. S30-S45, 2008.

[4] E. L. M. Ochoa and J. Lasalde-Dominicci, "Cognitive deficits in schizophrenia: focus on neuronal nicotinic acetylcholine receptors and smoking," Cellular and Molecular Neurobiology, vol. 27, no. 5, pp. 609-639, 2007.

[5] S. L. Cincotta, M. S. Yorek, T. M. Moschak, S. R. Lewis, and J. S. Rodefer, "Selective nicotinic acetylcholine receptor agonists: potential therapies for neuropsychiatric disorders with cognitive dysfunction," Current Opinion in Investigational Drugs, vol. 9, no. 1, pp. 47-56, 2008.

[6] I. Bacher, B. Wu, D. R. Shytle, and T. P. George, "Mecamylamine a nicotinic acetylcholine receptor antagonist with potential for the treatment of neuropsychiatric disorders," Expert Opinion on Pharmacotherapy, vol. 10, no. 16, pp. 2709 2721, 2009.

[7] E. X. Albuquerque, E. F. R. Pereira, M. Alkondon, and S. W. Rogers, "Mammalian nicotinic acetylcholine receptors: from structure to function," Physiological Reviews, vol. 89, no. 1, pp. 73-120, 2009.

[8] C. Gotti, M. Zoli, and F. Clementi, "Brain nicotinic acetylcholine receptors: native subtypes and their relevance," Trends in Pharmacological Sciences, vol. 27, no. 9, pp. 482-491, 2006.

[9] Y. Chen, L. M. Broad, K. G. Phillips, and R. Zwart, "Partial agonists for alpha4beta2 nicotinic receptors stimulate dopamine neuron firing with relatively enhanced maximal effects," British Journal of Pharmacology, vol. 165, no. 4, pp. 1006-1016, 2012.

[10] X. Li, D. G. Rainnie, R. W. McCarley, and R. W. Greene, "Presynaptic nicotinic receptors facilitate monoaminergic transmission," Journal of Neuroscience, vol. 18, no. 5, pp. 19041912, 1998.

[11] S. Mihailescu, R. Guzman-Marin, M. C Dominguez, and R. Drucker-Colin, "Mechanisms of nicotine actions on dorsal raphe serotoninergic neurons," European Journal of Pharmacology, vol. 452, no. 1, pp. 77-82, 2002.

[12] S. Mihailescu, M. Palomero-Rivero, P. Meade-Huerta, A. Maza-Flores, and R. Drucker-Colín, "Effects of nicotine and mecamylamine on rat dorsal raphe neurons," European Journal of Pharmacology, vol. 360, no. 1, pp. 31-36, 1998.

[13] B. W. Dunlop and C. B. Nemeroff, "The role of dopamine in the pathophysiology of depression," Archives of General Psychiatry, vol. 64, no. 3, pp. 327-337, 2007.

[14] J. Z. Guo, E. M. Sorenson, and V. A. Chiappinelli, "Cholinergic modulation of non-N-methyl-D-aspartic acid glutamatergic transmission in the chick ventral lateral geniculate nucleus.", Neuroscience, vol. 166, no. 2, pp. 604-614, 2010.

[15] H. Okuda, S. Shioda, Y. Nakai, H. Nakayama, M. Okamoto, and T. Nakashima, "The presence of corticotropin-releasing factor-like immunoreactive synaptic vesicles in axon terminals with nicotinic acetylcholine receptor-like immunoreactivity in the median eminence of the rat," Neuroscience Letters, vol. 161, no. 2, pp. 183-186, 1993.

[16] J. Raber, G. F. Koob, and F. E. Bloom, "Interleukin-2 (il2) induces corticotropin-releasing factor (crf) release from the amygdala and involves a nitric oxide-mediated signaling; comparison with the hypothalamic response," Journal of Pharmacology and Experimental Therapeutics, vol. 272, no. 2, pp. 815-824, 1995.

[17] A. H. Miller, V. Maletic, and C. L. Raison, "Inflammation and its discontents: the role of cytokines in the pathophysiology of major depression," Biological Psychiatry, vol. 65, no. 9, pp. 732-741, 2009.

[18] R. D. Shytle, T. Mori, K. Townsend et al., "Cholinergic modulation of microglial activation by $\alpha 7$ nicotinic receptors," Journal of Neurochemistry, vol. 89, no. 2, pp. 337-343, 2004.

[19] M. Gallowitsch-Puerta and V. A. Pavlov, "Neuro-immune interactions via the cholinergic anti-inflammatory pathway," Life Sciences, vol. 80, no. 24-25, pp. 2325-2329, 2007.

[20] J. T. Andreasen and J. P. Redrobe, "Nicotine, but not mecamylamine, enhances antidepressant-like effects of citalopram and reboxetine in the mouse forced swim and tail suspension tests," Behavioural Brain Research, vol. 197, no. 1, pp. 150-156, 2009.

[21] V. J. Djuric, E. Dunn, D. H. Overstreet, A. Dragomir, and M. Steiner, "Antidepressant effect of ingested nicotine in female rats of Flinders resistant and sensitive lines," Physiology \& Behavior, vol. 67, no. 4, pp. 533-537, 1999.

[22] J. Semba, C. Mataki, S. Yamada, M. Nankai, and M. Toru, "Antidepressantlike effects of chronic nicotine on learned helplessness paradigm in rats," Biological Psychiatry, vol. 43, no. 5, pp. 389-391, 1998.

[23] Y. Tizabi, D. H. Overstreet, A. H. Rezvani et al., "Antidepressant effects of nicotine in an animal model of depression," Psychopharmacology, vol. 142, no. 2, pp. 193-199, 1999.

[24] R. D. Porsolt, M. Le Pichon, and M. Jalfre, "Depression: a new animal model sensitive to antidepressant treatments," Nature, vol. 266, no. 5604, pp. 730-732, 1977.

[25] L. Steru, R. Chermat, B. Thierry, and P. Simon, "The tail suspension test: a new method for screening antidepressants in mice," Psychopharmacology, vol. 85, no. 3, pp. 367-370, 1985.

[26] R. J. Salin-Pascual, "Relationship between mood improvement and sleep changes with acute nicotine administration in nonsmoking major depressed patients," Revista De Investigacion Clinica, vol. 54, no. 1, pp. 36-40, 2002.

[27] F. J. McClernon, F. B. Hiott, E. C. Westman, J. E. Rose, and E. D. Levin, "Transdermal nicotine attenuates depression symptoms in nonsmokers: a double-blind, placebo-controlled trial," Psychopharmacology, vol. 189, no. 1, pp. 125-133, 2006.

[28] C. L. Gentry and R. J. Lukas, "Regulation of nicotinic acetylcholine receptor numbers and function by chronic nicotine exposure," Curr Drug Target Cns Neurol Disord, vol. 1, no. 4, pp. 359-385, 2002.

[29] K. G. Paradiso and J. H. Steinbach, "Nicotine is highly effective at producing desensitization of rat $\alpha 4 \beta 2$ neuronal nicotinic receptors," Journal of Physiology, vol. 553, no. 3, pp. 857-871, 2003.

[30] R. D. Shytle, A. A. Silver, R. J. Lukas, M. B. Newman, D. V. Sheehan, and P. R. Sanberg, "Nicotinic acetylcholine receptors 
as targets for antidepressants," Molecular Psychiatry, vol. 7, no. 6, pp. 525-535, 2002.

[31] Y. S. Mineur and M. R. Picciotto, "Biological basis for the comorbidity between smoking and mood disorders," Journal of Dual Diagnosis, vol. 5, no. 2, pp. 122-130, 2009.

[32] M. R. Picciotto, N. A. Addy, Y. S. Mineur, and D. H. Brunzell, "It is not "either/or": activation and desensitization of nicotinic acetylcholine receptors both contribute to behaviors related to nicotine addiction and mood," Progress in Neurobiology, vol. 84, no. 4, pp. 329-342, 2008.

[33] I. Bacher, R. Rabin, A. Woznica, K. A. Sacco, and T. P. George, "Nicotinic receptor mechanisms in neuropsychiatric disorders: therapeutic implications," Primary Psychiatry, vol. 17, no. 1, pp. 35-41, 2010.

[34] R. D. Shytle, A. A. Silver, K. H. Sheehan, D. V. Sheehan, and P. R. Sanberg, "Neuronal nicotinic receptor inhibition for treating mood disorders: preliminary controlled evidence with mecamylamine," Depression and Anxiety, vol. 16, no. 3, pp. 8992, 2002.

[35] P. Popik, E. Kozela, and M. Krawczyk, "Nicotine and nicotinic receptor antagonists potentiate the antidepressant-like effects of imipramine and citalopram," British Journal of Pharmacology, vol. 139, no. 6, pp. 1196-1202, 2003.

[36] R. L. Rabenstein, B. J. Caldarone, and M. R. Picciotto, "The nicotinic antagonist mecamylamine has antidepressant-like effects in wild-type but not $\beta 2$ - or $\alpha 7$-nicotinic acetylcholine receptor subunit knockout mice," Psychopharmacology, vol. 189, no. 3, pp. 395-401, 2006.

[37] B. J. Caldarone, A. Harrist, M. A. Cleary, R. D. Beech, S. L. King, and M. R. Picciotto, "High-affinity nicotinic acetylcholine receptors are required for antidepressant effects of amitriptyline on behavior and hippocampal cell proliferation," Biological Psychiatry, vol. 56, no. 9, pp. 657-664, 2004.

[38] J. T. Andreasen, G. M. Olsen, O. Wiborg, and J. P. Redrobe, "Antidepressant-like effects of nicotinic acetylcholine receptor antagonists, but not agonists, in the mouse forced swim and mouse tail suspension tests," Journal of Psychopharmacology, vol. 23, no. 7, pp. 797-804, 2009.

[39] Y. S. Mineur, O. Somenzi, and M. R. Picciotto, "Cytisine, a partial agonist of high-affinity nicotinic acetylcholine receptors, has antidepressant-like properties in male c57bl/6j mice," Neuropharmacology, vol. 52, no. 5, pp. 1256-1262, 2007.

[40] P. M. Lippiello, J. S. Beaver, G. J. Gatto et al., "Tc-5214 (S(+)-mecamylamine): a neuronal nicotinic receptor modulator with antidepressant activity," CNS Neuroscience and Therapeutics, vol. 14, no. 4, pp. 266-277, 2008.

[41] Association AP, Diagnostic and Statistical Manual of Mental Disorders, 4th, Washington, DC, USA.

[42] T. P. George, K. A. Sacco, J. C. Vessicchio, A. H. Weinberger, and R. D. Shytle, "Nicotinic antagonist augmentation of selective serotonin reuptake inhibitor-refractory major depressive disorder: a preliminary study," Journal of Clinical Psychopharmacology, vol. 28, no. 3, pp. 340-344, 2008.

[43] J. A. Dani and R. A. Harris, "Nicotine addiction and comorbidity with alcohol abuse and mental illness," Nature Neuroscience, vol. 8, no. 11, pp. 1465-1470, 2005.

[44] Targacept, http://www.targacept.com/wt/page/tc_5214.

[45] P. Tutka and W. Zatonski, "Cytisine for the treatment of nicotine addiction: from a molecule to therapeutic efficacy," Pharmacological Reports, vol. 58, no. 6, pp. 777-798, 2006.

[46] Y. S. Mineur, C. Eibl, G. Young et al., "Cytisine-based nicotinic partial agonists as novel antidepressant compounds," Journal of Pharmacology and Experimental Therapeutics, vol. 329, no. 1, pp. 377-386, 2009.
[47] C. H. Beck and H. C. Fibiger, "Chronic desipramine alters stress-induced behaviors and regional expression of the immediate early gene, c-fos," Pharmacol Biochem Behav, vol. 51, no. 2-3, pp. 331-338, 1995.

[48] D. A. Slattery, J. A. Morrow, A. L. Hudson, D. R. Hill, D. J. Nutt, and B. Henry, "Comparison of alterations in c-fos and egr-1 (zif268) expression throughout the rat brain following acute administration of different classes of antidepressant compounds," Neuropsychopharmacology, vol. 30, no. 7, pp. 1278-1287, 2005.

[49] R. West, W. Zatonski, M. Cedzynska et al., "Placebo-controlled trial of cytisine for smoking cessation," The New England Journal of Medicine, vol. 365, no. 13, pp. 1193-1200, 2011.

[50] G. A. Bentley and J. Starr, "The antinociceptive action of some $\beta$-adrenoceptor agonists in mice," British Journal of Pharmacology, vol. 88, no. 3, pp. 515-521, 1986.

[51] J. W. Coe, P. R. Brooks, M. G. Vetelino et al., "Varenicline: an alpha; $4 \beta 2$ nicotinic receptor partial agonist for smoking cessation," Journal of Medicinal Chemistry, vol. 48, no. 10, pp. 3474-3477, 2005.

[52] H. Rollema, V. Guanowsky, Y. S. Mineur et al., "Varenicline has antidepressant-like activity in the forced swim test and augments sertraline's effect," European Journal of Pharmacology, vol. 605, no. 1-3, pp. 114-116, 2009.

[53] J. R. Turner, L. M. Castellano, and J. A. Blendy, "Nicotinic partial agonists varenicline and sazetidine-a have differential effects on affective behavior," Journal of Pharmacology and Experimental Therapeutics, vol. 334, no. 2, pp. 665-672, 2010.

[54] D. E. Jorenby, J. T. Hays, N. A. Rigotti et al., "Efficacy of varenicline, an $\alpha 4 \beta 2$ nicotinic acetylcholine receptor partial agonist, vs placebo or sustained-release bupropion for smoking cessation: a randomized controlled trial," Journal of the American Medical Association, vol. 296, no. 1, pp. 56-63, 2006.

[55] D. Gonzales, S. I. Rennard, M. Nides et al., "Varenicline, an $\alpha 4 \beta 2$ nicotinic acetylcholine receptor partial agonist, vs sustained-release bupropion and placebo for smoking cessation: a randomized controlled trial," Journal of the American Medical Association, vol. 296, no. 1, pp. 47-55, 2006.

[56] F. Patterson, C. Jepson, A. A. Strasser et al., "Varenicline improves mood and cognition during smoking abstinence," Biological Psychiatry, vol. 65, no. 2, pp. 144-149, 2009.

[57] N. S. Philip, L. L. Carpenter, A. R. Tyrka, L. B. Whiteley, and L. H. Price, "Varenicline augmentation in depressed smokers: an 8-week, open-label study," Journal of Clinical Psychiatry, vol. 70, no. 7, pp. 1026-1031, 2009.

[58] A. P. Kozikowski, J. Brek Eaton, K. M. Bajjuri et al., "Chemistry and pharmacology of nicotinic ligands based on 6[5-(azetidin-2-ylmethoxy)pyridin-3-yl] hex-5-yn-1-ol (amoph-oh) for possible use in depression," Chemmedchem, vol. 4, no. 8, pp. 1279-1291, 2009.

[59] B. J. Caldarone, D. Wang, N. E. Paterson et al., "Dissociation between duration of action in the forced swim test in mice and nicotinic acetylcholine receptor occupancy with sazetidine, varenicline, and 5-i-a85380," Psychopharmacology, vol. 217, pp. 199-210, 2011.

[60] R. Freedman, "Exacerbation of schizophrenia by varenicline," American Journal of Psychiatry, vol. 164, no. 8, p. 1269, 2007.

[61] I. Kohen and N. Kremen, "Varenicline-induced manic episode in a patient with bipolar disorder [8]," American Journal of Psychiatry, vol. 164, no. 8, pp. 1269-1270, 2007.

[62] M. K. Popkin, "Exacerbation of recurrent depression as a result of treatment with varenicline," American Journal of Psychiatry, vol. 165, no. 6, p. 774, 2008. 
[63] T. J. Moore, C. D. Furberg, J. Glenmullen, J. T. Maltsberger, and S. Singh, "Suicidal behavior and depression in smoking cessation treatments," PLoS One, vol. 6, no. 11, article e27016, 2011.

[64] S. Tonstad, S. Davies, M. Flammer, C. Russ, and J. Hughes, "Psychiatric adverse events in randomized, double-blind, placebo-controlled clinical trials of varenicline: a pooled analysis," Drug Safety, vol. 33, no. 4, pp. 289-301, 2010.

[65] J. B. McClure, G. E. Swan, L. Jack et al., "Mood, side-effects and smoking outcomes among persons with and without probable lifetime depression taking varenicline," Journal of General Internal Medicine, vol. 24, no. 5, pp. 563-569, 2009.

[66] J. A. Stapleton, L. Watson, L. I. Spirling et al., "Varenicline in the routine treatment of tobacco dependence: a prepost comparison with nicotine replacement therapy and an evaluation in those with mental illness," Addiction, vol. 103, no. 1, pp. 146-154, 2008.

[67] D. Gunnell, D. Irvine, L. Wise, C. Davies, and R. M. Martin, "Varenicline and suicidal behaviour: a cohort study based on data from the general practice research database," BMJ, vol. 339, article b3805, 2009.

[68] U.S. Food and Drug Administration, "FDA drug safety communication: safety review update of Chantix (varenicline) and risk of neuropsychiatric adverse events," http://www.fda.gov/ Drugs/DrugSafety/ucm276737.htm.

[69] J. R. Hughes, "Depression during tobacco abstinence," Nicotine and Tobacco Research, vol. 9, no. 4, pp. 443-446, 2007.

[70] D. J. Anderson, J. Malysz, J. H. Gronlien et al., "Stimulation of dopamine release by nicotinic acetylcholine receptor ligands in rat brain slices correlates with the profile of high, but not low, sensitivity alpha4beta2 subunit combination," Biochemical Pharmacology, vol. 78, no. 7, pp. 844-851, 2009.

[71] H. Rollema, A. Shrikhande, K. M. Ward et al., "Pre-clinical properties of the $\alpha 4 \beta 2$ nicotinic acetylcholine receptor partial agonists varenicline, cytisine and dianicline translate to clinical efficacy for nicotine dependence," British Journal of Pharmacology, vol. 160, no. 2, pp. 334-345, 2010.

[72] S. Tonstad, I. Holme, and P. Tønnesen, "Dianicline, a novel $\alpha 4 \beta 2$ nicotinic acetylcholine receptor partial agonist, for smoking cessation: a randomized placebo-controlled clinical trial," Nicotine and Tobacco Research, vol. 13, no. 1, pp. 1-6, 2011.

[73] Y. Xiao, H. Fan, J. L. Musachio et al., "Sazetidine-a, a novel ligand that desensitizes $\alpha 4 \beta 2$ nicotinic acetylcholine receptors without activating them," Molecular Pharmacology, vol. 70, no. 4, pp. 1454-1460, 2006.

[74] J. Liu, L. F. Yu, J. B. Eaton et al., "Discovery of isoxazole analogues of sazetidine-A as selective alpha4beta2-nicotinic acetylcholine receptor partial agonists for the treatment of depression," Journal of Medicinal Chemistry, vol. 54, no. 20, pp. 7280-7288, 2011.

[75] L. F. Yu, W. Tuckmantel, J. B. Eaton et al., "Identification of Novel alpha4beta2-Nicotinic Acetylcholine Receptor (nAChR) agonists based on an isoxazole ether scaffold that cemonstrate antidepressant-like activity," Journal of Medicinal Chemistry, vol. 55, no. 2, pp. 812-823, 2012.

[76] H. Zhang, W. Tuckmantel, J. B. Eaton et al., "Chemistry and behavioral studies identify chiral cyclopropanes as selective alpha4beta2-Nicotinic Acetylcholine receptor partial agonists exhibiting an antidepressant profile," Journal of Medicinal Chemistry, vol. 55, no. 2, pp. 717-724, 2012.

[77] L. Maggi, E. Palma, R. Miledi, and F. Eusebi, "Effects of fluoxetine on wild and mutant neuronal $\alpha 7$ nicotinic receptors," Molecular Psychiatry, vol. 3, no. 4, pp. 350-355, 1998.
[78] J. T. Andreasen, E. O. Nielsen, J. K. Christensen et al., "Subtype-selective nicotinic acetylcholine receptor agonists enhance the responsiveness to citalopram and reboxetine in the mouse forced swim test," Journal of Psychopharmacology, vol. 25, no. 10, pp. 1347-1356, 2011.

[79] J. T. Andreasen, J. P. Redrobe, and E. O. Nielsen, "Combined alpha7 nicotinic acetylcholine receptor agonism and partial serotonin transporter inhibition produce antidepressant-like effects in the mouse forced swim and tail suspension tests: a comparison of SSR180711 and PNU-282987," Pharmacology Biochemistry and Behavior, vol. 100, no. 3, pp. 624-629, 2012.

[80] V. Voikar, S. Koks, E. Vasar, and H. Rauvala, "Strain and gender differences in the behavior of mouse lines commonly used in transgenic studies," Physiology \& Behavior, vol. 72, no. 1-2, pp. 271-281, 2001.

[81] D. P. Walker, D. G. Wishka, D. W. Piotrowski et al., "Design, synthesis, structure-activity relationship, and in vivo activity of azabicyclic aryl amides as $\alpha 7$ nicotinic acetylcholine receptor agonists," Bioorganic and Medicinal Chemistry, vol. 14, no. 24, pp. 8219-8248, 2006. 

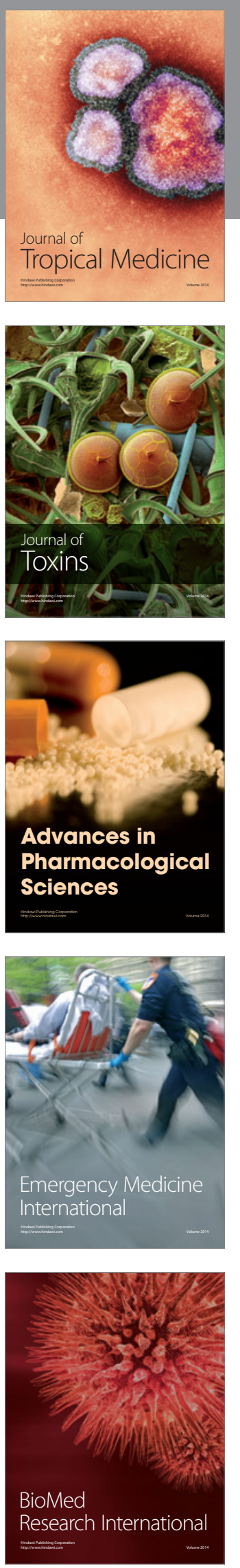
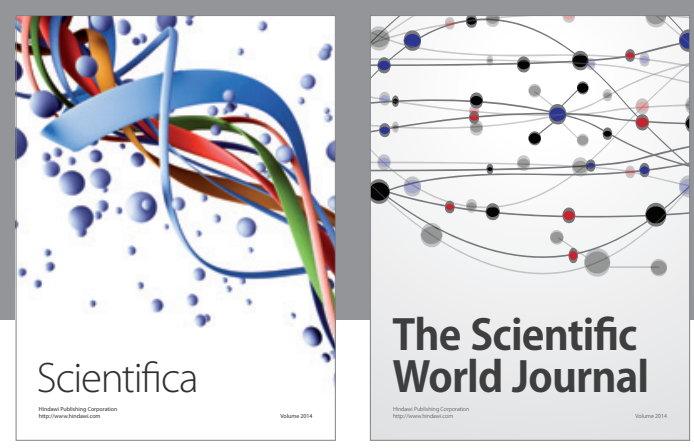

The Scientific World Journal
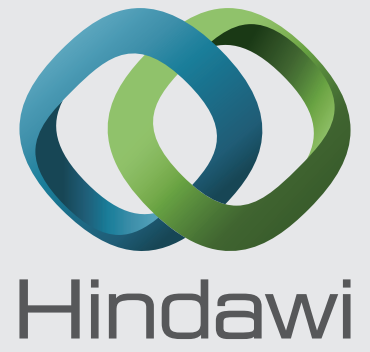

Submit your manuscripts at

http://www.hindawi.com
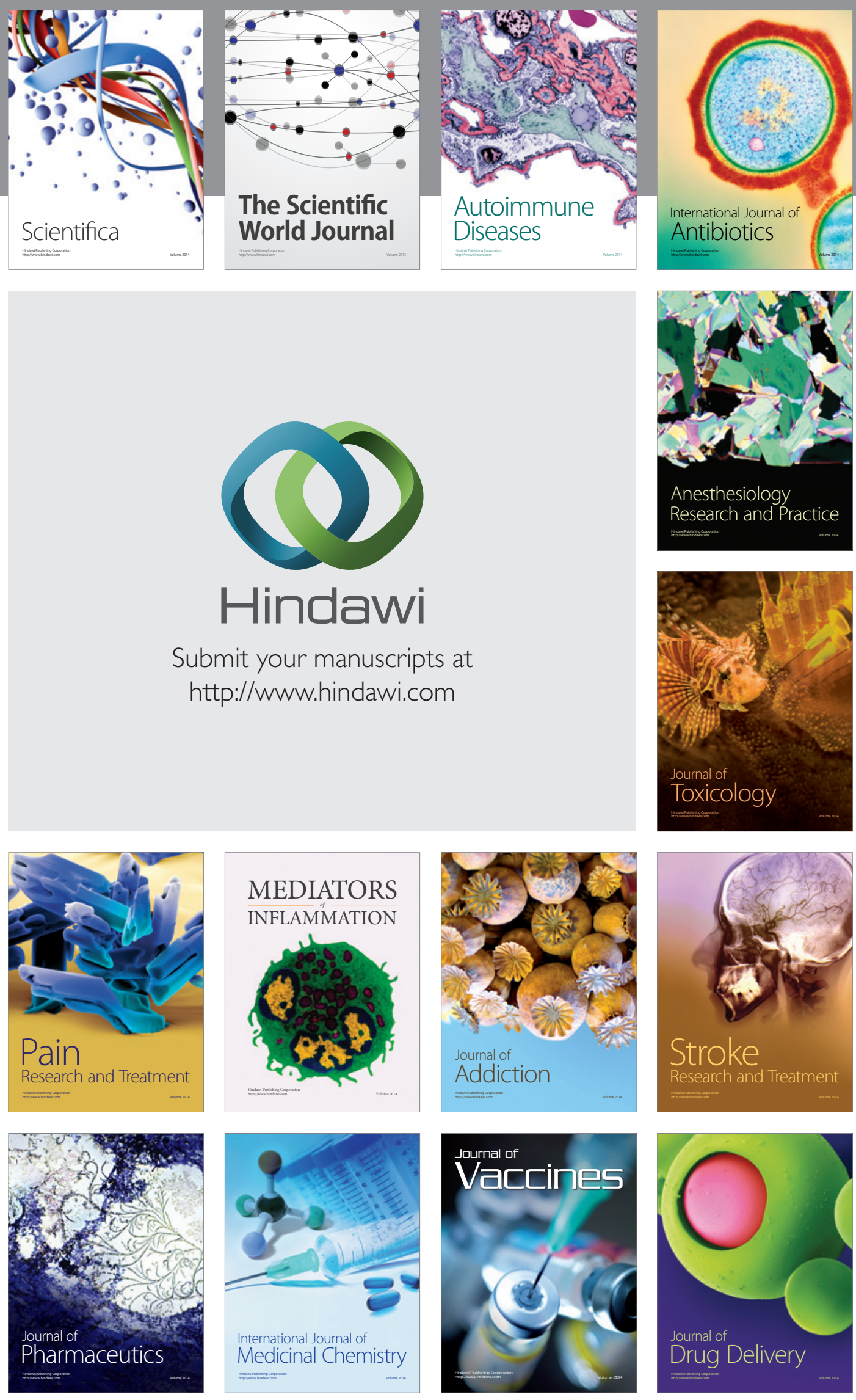